\title{
NEW RECORDS OF Hipposideros griffini FROM LAVA CAVES AND THE THREATS TO ITS CONSERVATION IN VIETNAM
}

\author{
Vu Dinh Thong ${ }^{1,2}$ \\ ${ }^{1}$ Institute of Ecology and Biological Resources, VAST, Vietnam \\ ${ }^{2}$ Graduate University of Science and Technology, VAST, Vietnam
}

Received 2 August 2019, accepted 28 November 2019

\begin{abstract}
Lava caves are unique and fragile ecosystems which are suitable for a wide variety of plant and animal species. However, the biodiversity of lava caves is still poorly studied. To increase knowledge of these special ecosystems, several rapid surveys on bats were carried out in Dak Nong Province in sounthern Vietnam between 2014 and 2019. Bats were captured in the field using mist nets and harp traps. Echolocation calls were recorded in different situations using the PCTape system. The results include records of Griffin's leaf-nosed bat (Hipposideros griffini) which is regarded as a species endemic to Vietnam only. Prior to the present study, it was only recorded from karst and moutain habitats in three different regions of Vietnam: Cat Ba National Park in the northeast, Chu Mom Ray in the central highlands, and Cat Tien National Park in the southeast. Records of Hipposideros griffini from Dak Nong Province extend its distributional range and highlight the importance of lava cave systems for biodiversity research and conservation in Vietnam. Griffin's leaf-nosed bat and other animal species inhabiting the lava caves have been critically threatened by hunting and other human activities. Morphological measurements and echolocation calls of Hipposideros griffini together with the threats to its conservation status in Dak Nong Province are given in this paper.
\end{abstract}

Keywords: Hipposideridae, Chiroptera, Mammalia, volcanic ecosystem, conservation.

Citation: Vu Dinh Thong, 2019. New records of Hipposideros griffini from lava caves and the threats to its conservation in Vietnam. Academia Journal of Biology, 41(4): 31-36. https://doi.org/10.15625/26159023/v41n4.14487.

Corresponding author email: thongvudinh@gmail.com

(C2019 Vietnam Academy of Science and Technology (VAST) 


\section{INTRODUCTION}

Lava caves, also known as volcanic lava tubes, play important roles in natural ecosystems, human history, and culture (Phuc et al., 2018a; Phuc et al., 2018b). To date, lava caves of Vietnam are located in the central highlands and south-eastern region (La The Phuc, pers.com.). Vietnam contains the four longest lava caves in South East Asia (Phuc et al., 2018b). However, lava caves are poorly studied but are threatened by human activities. Many new species and unusual forms of animals and plants have been discovered in lava caves (Saw at el., 2013; Poupin et al., 2018).

Griffin's leaf-nosed bat belongs to the family Hipposideridae which currently comprises 90 species worldwide (Thong et al., 2012; Simmons \& Cirranello, 2019). To date, this species has been regarded only endemic to Vietnam with records from three national parks of the country: Cat Ba, Chu Mom Ray, and Cat
Tien (Thong, 2012; Thong et al., 2012). The previous records of this species were from karst landscapes, mountainous and flatland habitats. Between 2014 and 2019, several rapid surveys on bats were carried out through the lava caves in the central highlands and south eastern regions of Vietnam. The results from the surveys include records of a rarely documented bat species, Hipposideros griffini. Unfortunately, Griffin's leaf-nosed bat and other species inhabiting lava caves are critically threatened by human activities. This paper provides details of the records of Hipposideros griffini and the threats to its conservation status in Dak Nong Province.

\section{MATERIALS AND METHODS}

The present study was carried out at five caves, namely $\mathrm{C} 0-\mathrm{C} 4$, in the Krongno Volcano Geopark, Dak Nong Province, the Central Highlands, Vietnam. Coordinates and altitudes (metre above sea level) of these caves are given in the table 1.

Table 1. Coordinates and relevant information of the five studied caves

\begin{tabular}{|c|c|c|c|c|}
\hline \multirow{2}{*}{ Cave ID } & \multicolumn{2}{|c|}{ Coordinates } & \multirow{2}{*}{$\begin{array}{l}\text { Altitude } \\
\text { (m a.s.l.) }\end{array}$} & \multirow{2}{*}{ Bat species recorded } \\
\hline & Latitude & Longitude & & \\
\hline $\mathrm{C} 0$ & $12^{\circ} 31^{\prime} 15^{\prime \prime} \mathrm{N}$ & $107^{\circ} 533^{\prime} 39^{\prime \prime} \mathrm{E}$ & 380.3 & Hipposideros cineraceus, Rhinolophus pusillus \\
\hline $\mathrm{C} 1$ & $12^{\circ} 31^{\prime} 09^{\prime \prime} \mathrm{N}$ & $107^{\circ} 53^{\prime} 29^{\prime \prime} \mathrm{E}$ & 361.1 & H. griffini (ca. 30 individuals), R. pusillus \\
\hline $\mathrm{C} 2$ & $12^{\circ} 31^{\prime} 06^{\prime \prime} \mathrm{N}$ & $107^{\circ} 53^{\prime} 42^{\prime \prime} \mathrm{E}$ & 392.9 & H. griffini, H. cineraceus, $R$. pusillus, Rhinolophus sp. 2 \\
\hline $\mathrm{C} 3$ & $12^{\circ} 30^{\prime} 59^{\prime \prime} \mathrm{N}$ & $107^{\circ} 53^{\prime} 54^{\prime \prime} \mathrm{E}$ & 400.6 & H. griffini, Rhinolophus sp.1 \\
\hline $\mathrm{C} 4$ & $12^{\circ} 30^{\prime} 53^{\prime \prime} \mathrm{N}$ & $107^{\circ} 53^{\prime} 59^{\prime \prime} \mathrm{E}$ & 401.8 & H. griffini, Hipposideros galeritus, Rhinolophus sp.1 \\
\hline
\end{tabular}

\section{Bat capture and examination}

Bats were captured and handled in the field following the guidelines approved by the American Society of Mammalogists (Sikes \& ACUCASM, 2016). One four-bank harp trap (Francis, 1989) and three mist nets of various sizes $(2.6 \mathrm{~m}$ [height], 3-9 m [length], mesh size: $16 \mathrm{~mm} \times 16 \mathrm{~mm}$ ) were employed to capture bats. The captured bats were removed carefully from the trap or net and placed individually in a cotton bag (Thong, 2011). The following external measurements were taken in the field using a digital caliper to the nearest $0.1 \mathrm{~mm}$. FA, forearm length - from the extremity of the elbow to the extremity of the carpus with the wings folded; EH, ear height - length of ear conch; EW, ear width - the greatest width of ear conch; TIB, tibia length-from the knee joint to the ankle; HF, hind-foot lengthfrom the extremity of the heel behind the $O s$ calcis to the extremity of the longest digit, excluding the hairs or claws. Each of these five selected measurements was taken following the same protocol (Thong et al., 2012) and they are illustrated in Bates and Harrison (1997) and Csorba et al. (2003). Reproductive status and ages were respectively assessed following Racey (2009) and Brunet-Rossinni and Wilkinson (2009). Data from all juveniles were excluded from analyses. 


\section{Recording and analysis of echolocation calls}

Echolocation calls were recorded in three situations inside a flight-tent ( $4 \mathrm{~m}$ [length] $\times 4$ $\mathrm{m}$ [width] $\times 3 \mathrm{~m}$ [height]): handheld $(\mathrm{H})$, resting $(\mathrm{R})$ on the wall or ceiling, and flying (F) using the PCTape system at a sampling rate of $480 \mathrm{kHz}$. Batman software was used to select high quality sound sequences before recording. Recordings were also carried out in front of caves to obtain reference calls when bats were leaving their roosts. Recorded calls were analysed using Selena software to measure the constant frequency of the second harmonic $\left(\mathrm{CF}_{2}\right)$ of each call. We displayed the calls as colour spectrograms with durations of 50 milliseconds, a frequency range between $55-95 \mathrm{kHz}$ (FFT 1024) and used the cursor to determine the frequency of the CFcomponent. The PCTape system, Batman and Selena softwares are custom-made by the University of Tübingen, Germany.

\section{RESULTS}

A total of 12 bats were captured during the survey in Dak Nong Province in April 2019. Of these, seven lactating females were released immediately after careful removal from the harp trap and nets and the residual 5 bats were examined further (table 1). Morphological characteristics and measurements of all captured individuals confirm the identity of Hipposideros griffini (Fig. 1). Their pelage colour is dark brown; the dorsal fur is darker than the ventral. With forearm length of $88.4-91.2 \mathrm{~mm}(\mathrm{n}=5)$, all captured individuals of $H$. griffini are distinguishable from other bat species by body size. Other measurements (EH: 24.2-26.9 mm; EW: 16.6-24.0 mm; TIB: $33.8-37.8 \mathrm{~mm}$; HF: $12.9-14.8 \mathrm{~mm}$ ) also supported that $H$. griffini is the largest insectivorous bat species of the study area. Their nose leaves are fleshy and naked with four pairs of supplementary lateral leaflets. The outgrowth and sexual sac behind the posterior leaf of all captured males were well-developed. Together with enlarged pubic nipples of females, these features indicate that Hipposideros griffini in Dak Nong Province is reproductively active in April.

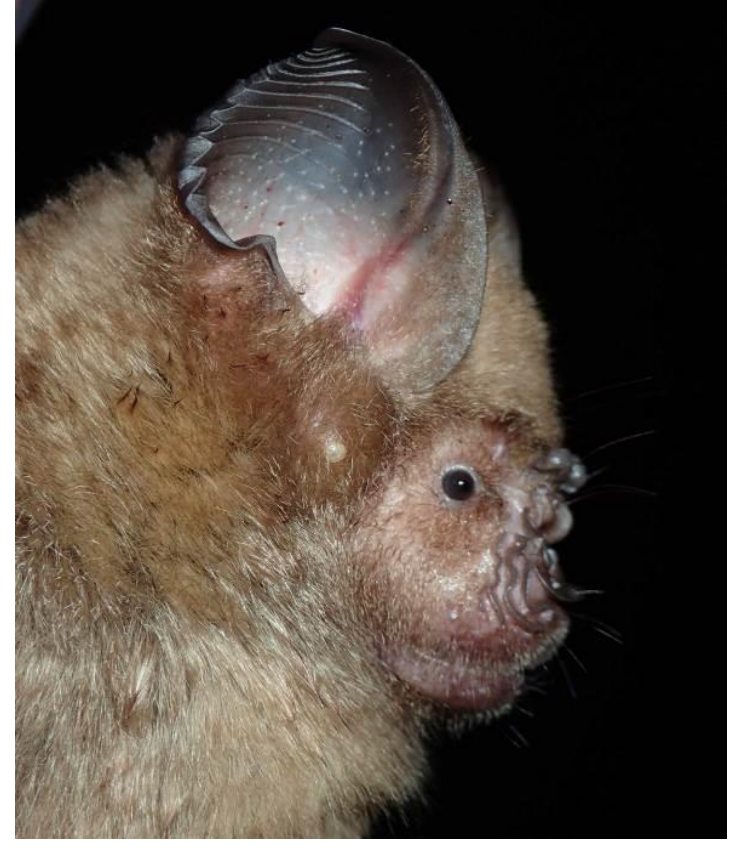

Figure 1. Lateral view of the ear and the face of Hipposideros griffini from lava caves, Dak Nong Province

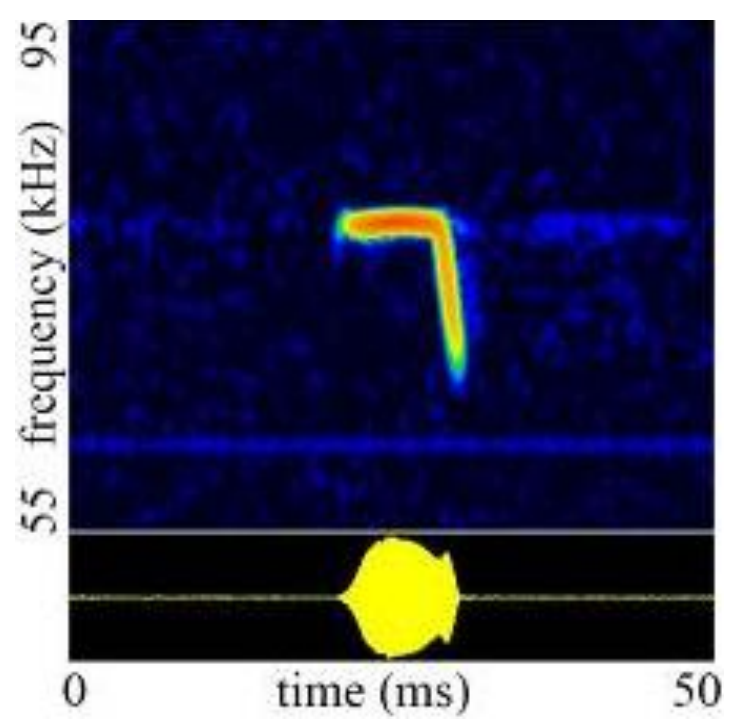

Figure 2. Echolocation call of Hipposideros griffini from lava caves, Dak Nong Province

All recordings exhibit the typical multiharmonic calls of hipposiderid bats, with three components (narrow initial frequency modulated, constant frequency (CF) and narrow terminal frequency). Frequency values 
of the constant frequency component of the second harmonic $\left(\mathrm{CF}_{2}\right)$ are in a range of 76.1$79.7 \mathrm{kHz}$ (Fig. 2). There is no significant difference in $\mathrm{CF} 2$ of the calls from different recording situations.

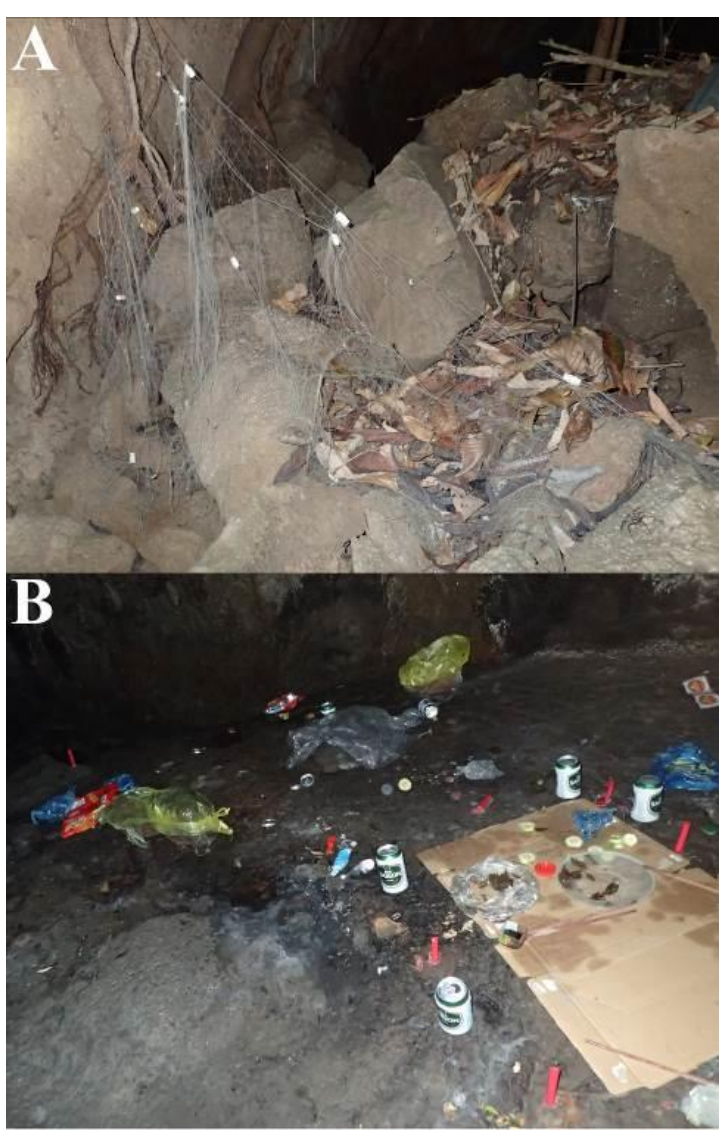

Figure 3. Evidence of hunting and disturbance by tourism activities at lava caves, Dak Nong Province

Bats and other animal species of the lava caves appear to have been threatened by hunting and habitat loss. During this study, evidence of bat hunting and disturbance by cave tourism is clearly visible at the study caves (Fig. 3). Due to lack of knowledge regarding the importance of bats and bat conservation, local people and workers from other localities hunt bats for food and fun. Roosting sites of $H$. griffini and other bat species in the lava caves are also disturbed.

\section{DISCUSSION}

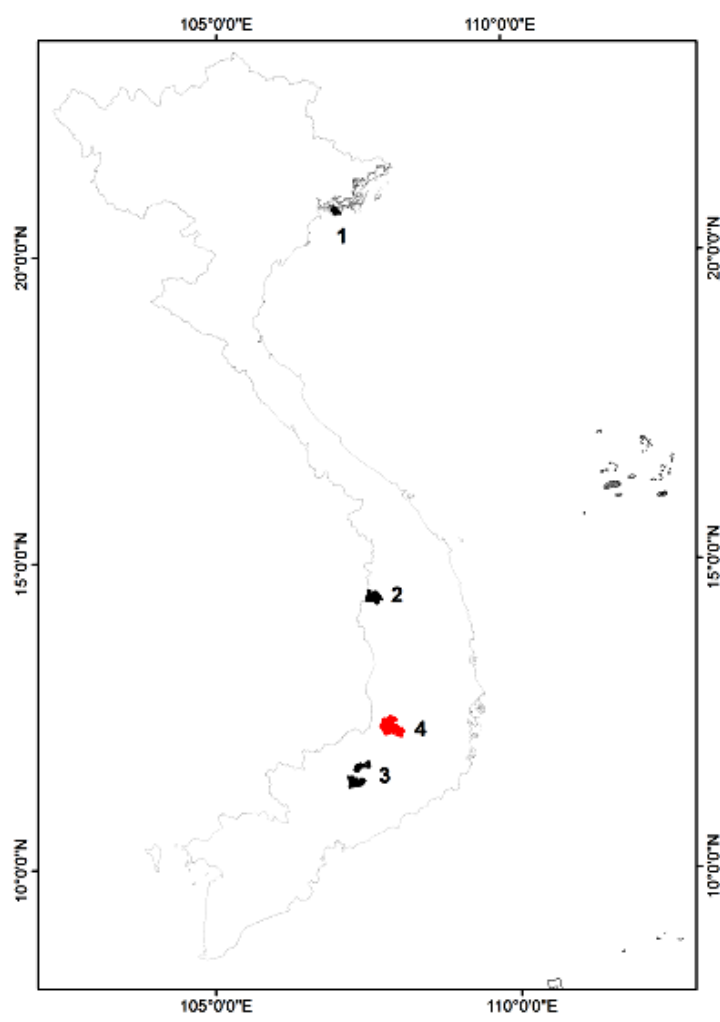

Figure 4. Previous and present records of Hipposideros griffini (1: Cat Ba National Park; 2: Chu Mom Ray National Park; 3: Cat Tien National Park; 4: Krong No area, Dak Nong Province; map by Nguyen Tran Vy)

Taxonomic and acoustic characteristics of H. griffini from Dak Nong Province are identical to those described in the published literature (Thong, 2012; Thong et al., 2012; Fig. 4; table 2). Records of $H$. griffini in Dak Nong not only expand the distributional range of the species, but also increase knowledge about its roosting sites from karst caves to lava tube caves. To date, neither population nor colony size of $H$. griffini is known. The species live in groups of up to ca. 30 individuals in lava caves of Dak Nong Province. Thong et al. (2012) and Thong (2012) recorded 11 other bat species from the same roosting sites with Griffin's leaf-nosed bat: Aselliscus stoliczkanus, $H$. cineraceus, $H$. galeritus, $H$. larvatus, $H$. cf. pomona, $H$. alongensis, 
Rhinolophus affinis, $R$. chaseni, R. pusillus, $R$. macrotis and Myotis rosseti. Within the lava caves in Dak Nong Province, six other bat species-level recorded at the same site with $H$. griffini included $H$. cineraceus, $H$. galeritus, $R$. pusillus, Rhinolophus sp1, Rhinolophus sp2.
The echolocation calls of Rhinolophus sp1, Rhinolophus $\mathrm{sp} 2$ with respective $\mathrm{CF} 2$ values of $35.0 \mathrm{kHz}$ and $121.0 \mathrm{kHz}$ were recorded from two different lava caves. Further surveys are required to confirm the occurrence of these species-level in Dak Nong Province.

Table 2. Comparative measurements of Hipposideros griffini from Dak Nong Province and other localities

\begin{tabular}{|c|c|c|c|}
\hline \multirow{2}{*}{ Measurements } & \multicolumn{3}{|c|}{ Localities } \\
\cline { 2 - 4 } & Dak Nong & Cat Ba \& Chu Mom Ray $\dagger$ & Cat Tien† $\dagger$ \\
\hline FA & $88.4-91.2$ & $83.3-90.0$ & $83.0-90.5$ \\
\hline EH & $24.2-26.9$ & $27.5-30.0$ & $27.0-30.3$ \\
\hline EW & $16.6-24.0$ & $23.5-26.5$ & $22.6-26.8$ \\
\hline TIB & $33.8-37.8$ & $36.4-41.1$ & $34.8-40.5$ \\
\hline HF & $12.9-14.8$ & $14.1-15.8$ & $14.0-16.0$ \\
\hline CF2 & $76.1-79.7$ & $75.5-79.2$ & $75.3-79.5$ \\
\hline
\end{tabular}

Notes: $\dagger=$ Thong et al. (2012); $\dagger \dagger=$ Thong (2012).

Frick et al. (2019) indicated that hunting is one of the most widespread and critical threats to bats worldwide. Griffin's leaf-nosed bat in Dak Nong Province has also been critically hunted by local people and workers from other localities over recent decades (Phuc et al., 2018b). Those species surviving in the studied caves are found in small groups of several to less than 30 individuals. Without urgent action for bat conservation at the study site, Griffin's leaf-nosed bat and other lava cave-dwelling species will be locally extinct in the very near future. Data from the recent rapid survey suggested that the lava caves and surrounding habitats are suitable for a highly diverse bat fauna. A project or programme is urgently needed for both research and conservation of bats in Dak Nong Province. To date, only 5 of the 45 lava caves, which are found in the Krongno Volcano Geopark, Dak Nong Province, have been rapidly surveyed for bats. Further bat surveys should be carried out through all known caves of the geopark to determine the current diversity, distribution and conservation status of each recorded species. Hunting must be prohibited as soon as possible by local law or regulation. Informal and formal meetings with involvement of the authorities and bat hunters must be organised to increase their knowledge about the importance of bats in ecosystems and their conservation. Building fences and gates based on scientific recommendations is also urgently needed for minimising the damage by tourism and other activities.

Acknowledgments: This research is funded by the Vietnam National Foundation for Science and Technology Development (NAFOSTED) under a grant number 106.05-2017.35; the Tay Nguyen Programme for the period 2016-2020 under a grant number TN17/T06. Particular thanks are extended to the Directorate of the Institute of Ecology and Biological Resources (IEBR), VAST; N.T. Minh, L.T. Phuc, P.D. Sac, P.H. Thai of the Vietnam National Museum for Nature, VAST; Nguyen Tran Vy, the Institute of Tropical Biology, VAST; to H.U. Schnitzler, A. Denzinger, C. Dietz, and I. Dietz of the University of Tuebingen, Germany; N.M. Furey of the Fauna and Flora International, Cambodia; P. J. J. Bates of the Harrison Institute, England; P. A. Racey of the University of Exeter, UK; and T. Kingston of the Texas Tech University, USA, for their various support.

\section{REFERENCES}

Bates P. J. J., Harrison D. L., 1997. Bats of the Indian Subcontinent. Harrison 
Zoological Museum, Sevenoaks, Kent, United Kingdom, 297 pp.

Brunet-Rossinni A. K., Wilkinson G. S., 2009. Methods for age estimation and the study of senescence in bats. In: Kunz T.H., Parsons S. (eds.) Ecological and Behavioral Methods for the Study of Bats, 2nd edition, Johns Hopkins University Press, Baltimore, pp. 315-325.

Csorba G., Ujhelyi P., Thomas N., 2003. Horseshoe Bats of the World (Chiroptera: Rhinolophidae). Alana Books, England.

Francis C. M., 1989. A comparison of mist nets and two types of harp traps for capturing bats. Journal of Mammalogy, 70: 865-870.

Frick W. F., Kingston T., Flanders J., 2019. A review of the major threats and challenges to global bat conservation. Annals of the New York Academy of Sciences, special issue in April 2019: 1-21.

Phuc L. T., Honda T., Tachihara H., Tuat L. T., Thom B. V., Hoang N., Chikano Y., Yoshida K., Hung N. B., Vu P. G. M., Duc T. M., Thai P. H., Sac P. D., Su N. K., Cuong N. L., Lan L. T. P., Hoa N. T. M., Tung N. T., Danh P. N., Minh N. T., 2018a. Lava Caves, Lava Formations And Biological And Archaeological Values Firstly Discovered In Krongno Volcano Geopark, Dak Nong, Vietnam. Proceedings of the Commission on volcanic caves, 18: 1-10.

Phuc L. T., Tachihara H., Honda T., Tuat L. T., Thom B. V., Hoang N., Chikano Y., Yoshida K., Tung N. T., Danh P. N., Hung N. B., Duc T. M., Vu P. G. M., Hoa N. T. M., Bien H. T., Quy T. Q., Minh N. T., 2018b. Geological values of lava caves in Krongno Volcano Geopark, Dak Nong, Vietnam. Vietnam Journal of Earth Sciences, 40(4): 299-319.

Poupin J., Crestey N., Guelte J.-P., 2018. Cave-dwelling crabs of the genus Karstarma from lava tubes of the volcano 'Piton de la Fournaise', in Réunion Island, with description of a new species and redescription of Karstarma jacksoni (Balss, 1934) from Christmas Island (Decapoda, Brachyura, Sesarmidae). Zootaxa, 4497(3): 381-397.

Racey P. A., 2009. Reproductive assessment in bats. Pp. 249-264 in Ecological and Behavioral Methods for the Study of Bats (T.H. Kunz and S. Parsons, eds.). $2^{\text {nd }}$ ed. Johns Hopkins University Press, Baltimore.

Saw J. H. W., Schatz M., Brown M. V., Kunkel D. D., Foster J. S., Shick H., Christensen S., Hou S., Wan X., Donachie S. P., 2013. Cultivation and Complete Genome Sequencing of Gloeobacter kilaueensis sp. nov., from a Lava Cave in K1 lauea Caldera, Hawai'i. PLOS ONE, 8(10), e76376: 1-12.

Sikes R. S., ACUCASM (the Animal Care and Use Committee of the American Society of Mammalogists), 2016. Guidelines of the American Society of Mammalogists for the use of wild mammals in research and education. Journal of Mammalogy, 97(3): 663-688.

Simmons N.B., Cirranello A.L., 2019. Bat Species of the World: A taxonomic and geographic database. Accessed on 11/12/2019.

Thong V. D., 2011. Systematics and echolocation of rhinolophoid bats (Mammalia: Chiroptera) in Vietnam. PhD Thesis, University of Tuebingen, Tuebingen, Germany, 258 pp.

Thong V. D., 2012. New records of Griffin's Leaf-nosed bat (Hipposideros griffini Thong et al. 2012) from Vietnam. Tap chi Sinh hoc (Journal of Biology), 34(3): 323-327.

Thong V. D., Puechmaille S. J., Denzinger A., Dietz C., Csorba G., Bates P. J. J., Teeling E. C., Schnitzler H. U., 2012. A new species of Hipposideros (Chiroptera: Hipposideridae) from Vietnam. Journal of Mammalogy, 93: 1-11. 

